\title{
Incidence of sudden unexpected death in an adult outpatient cohort with epilepsy at a tertiary referral centre
}

\author{
L Nashef, D R Fish, J W A S Sander, S D Shorvon
}

\begin{abstract}
Overall mortality, incidence of sudden unexpected death, and cause of death were determined in 601 adult outpatients with epilepsy at a tertiary referral centre. The patients were followed up from 1990 to 30 June 1993. There were 24 deaths among the 601 patients (1849 patient years) with a standardised mortality ratio of $5 \cdot 1 \quad(95 \%$ confidence interval 3.3-7.6) of which 14 were related to epilepsy. Underlying disease of which epilepsy was a symptom accounted for four deaths only. An incidence of sudden deaths (including seizure related) was of the order of $1: 200 / y e a r$.

In conclusion, excess mortality in chronic epilepsy is more likely to be related to the epilepsy itself than to underlying pathology. The relatively high incidence of sudden deaths found in this hospital based cohort has important implications for patient management.
\end{abstract}

(F Neurol Neurosurg Psychiatry 1995;58:462-464)

Keywords: sudden death; epilepsy; mortality

Mortality in patients with epilepsy is reported to be two to three times greater than that of the general population. ${ }^{1}$ In cases of recent onset, excess deaths are mainly due to underlying disease, whereas in chronic cases, they are primarily related to epilepsy with patients more likely to die of accidents, suicide, status epilepticus, and sudden unexpected death that may occur during or shortly after a

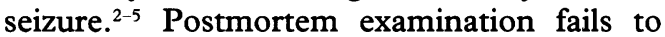
show an anatomical or toxicological cause of death. Evidence for an associated seizure is found in some $50 \%$ of cases and a history of generalised tonic clonic seizures is reported in most. ${ }^{3}$ Such deaths may constitute between $7.5 \%$ and $17 \%$ of deaths in patients with epilepsy. ${ }^{2}$ Estimates of incidence vary considerably, from $1: 200$ to $1: 1200 /$ year with a recent population based study reporting an incidence of $1 \cdot 3 / 1000 /$ year among patients with epilepsy aged 15-49 years. ${ }^{6}$ In a study of adult patients with chronic epilepsy in long term residential care, ${ }^{7}$ incidence of sudden deaths, including those related to seizure, was 1:260/year. The current study was designed to establish the incidence of sudden unexpected death in a hospital outpatient cohort with epilepsy.

\section{Methods}

The cohort under study included patients with active epilepsy seen in 1990 in designated specialist epilepsy clinics at the National Hospital for Neurology and Neurosurgery (three sites). Patients were identified from outpatient appointment lists or copies of clinic letters. Active epilepsy was defined to include patients who had had one or more seizures in the past five years or patients in remission on antiepileptic treatment including patients with a single event or provoked seizures.

The date of entry to the study was that of the first outpatient visit to one of the designated clinics in 1990. Date of completion of follow up was 30 June 1993. Those who had made contact in 1993 without missing any subsequent appointments were considered alive. General practitioners, or the relevant Family Service Health Authority, or both were otherwise contacted. A few patients were traced through the central register held by the Office of Population Censuses and Surveys (Southport).

Medical notes were reviewed for the whole cohort and the epilepsy syndrome recorded. Information on deaths was collected from general practitioners, hospital records, postmortem reports, coroners' reports, and death certificates as well as from information available soon after death to attending medical staff.

Standardised mortality ratios (SMRs) were calculated on the basis of person years in fiveyear age bands ${ }^{89}$ and on published 1991 mortality statistics for England and Wales. ${ }^{10}$ The SMR is the ratio of deaths observed in a group to the numbers of deaths that would be expected during the follow up period if the group in question had experienced the same age and sex specific death rates as the general population. ${ }^{11}$ The study was approved by the local ethics committee.

\section{Results}

CHARACTERISTICS OF THE COHORT

The cohort comprised 601 patients (330 male, 271 female) with an age range of 10-80 
Table 1 Epilepsy diagnosis in the cohort

\begin{tabular}{lcl} 
& $\begin{array}{l}\text { Total } \\
n(\%)\end{array}$ & $\begin{array}{l}\text { Sudden } \\
\text { deaths } \\
n(\%)\end{array}$ \\
\hline $\begin{array}{l}\text { Localisation related: } \\
\text { Symptomatic or cryptogenic }\end{array}$ & $401(66 \cdot 7)$ & $5(45 \cdot 4)$ \\
$\begin{array}{l}\text { Generalised epilepsy: } \\
\text { Idiopathic }\end{array}$ & $76(12 \cdot 6)$ & $1(9 \cdot 1)$ \\
$\begin{array}{l}\text { Generalised epilepsy: } \\
\text { Cryptogenic/symptomatic }\end{array}$ & $47(7 \cdot 8)$ & $3(27 \cdot 3)$ \\
$\begin{array}{l}\text { (nine specific syndromes) } \\
\text { Undetermined }\end{array}$ & $65(10 \cdot 8)$ & $2(18 \cdot 2)$ \\
$\begin{array}{l}\text { Situation related } \\
\text { (three provoked, one isolated) }\end{array}$ & $4(0 \cdot 7)$ & - \\
\begin{tabular}{l} 
Unknown \\
\hline
\end{tabular} & $8(1 \cdot 3)$ & - \\
\hline
\end{tabular}

and mean age of 32.5 years $(88 \%$ of the patients were aged between 15 and 45 ). Total follow up amounted to 1849 patient-years (average 3.076 years per patient). Mean duration of epilepsy was 19 years (range less than one to 63 years; $1 \cdot 3 \%$ unknown). Table 1 lists the syndromic diagnosis of epilepsy based on the modified 1989 International League Against Epilepsy classification. ${ }^{12}$

\section{OVERALL MORTALITY}

Only one patient from the cohort of 601 was not traced; three other patients had moved abroad during the period under study. All four were considered alive for the purpose of analysis. A total of 24 patients died (mean age at death 35 , range $18-73$ ) during the follow up period, representing an overall mortality of 1:77 per year and an SMR of 5.1 (95\% confidence interval (95\% CI) $3 \cdot 3-7 \cdot 6)$; $4.4(95 \%$ CI $2 \cdot 4-7 \cdot 5)$ for men and $6.3(95 \%$ CI 3.2-11.3) for women. Table 2 lists the causes of death. In five of 24 cases $(21 \%)$ the medical staff of the clinic were unaware that the patient had died.

\section{SUDDEN UNEXPECTED DEATHS: INCLUDING THOSE RELATED TO SEIZURES}

There were 11 unexpected sudden deaths (six females, five males) among the cohort. Only one was not referred to the coroner and was certified in the community as having died of an epileptic seizure. In two female patients, both reported as being well on the day of death, additional factors were present. One had an incidental one week old subdural haematoma at postmortem that was not thought to be the cause of death. Another, with known chronic renal failure and evidence in favour of a convulsion immediately

Table 2 Classification of deaths observed

\begin{tabular}{|c|c|}
\hline $\begin{array}{l}\text { Neoplasms } \\
\text { Accidental } \dagger \\
\text { Spontaneous intracerebral haemorrhage } \neq \\
\text { Sudden unexpected deaths } ₫ \\
\text { Status (complications thereof) } \\
\text { Other } 9 \\
\text { Total }\end{array}$ & $\begin{array}{r}5 \\
3 \\
2 \\
11 \\
1 \\
2 \\
24\end{array}$ \\
\hline $\begin{array}{l}\text { Two gliomas, one each acute myeloi } \\
\text { chondrosarcoma, and lung adenocarcinon } \\
\text { Two head injuries (one witnessed fit rel } \\
\text { n bath. } \\
\text { Ine vascular malformation, one bleed in } \\
\text { Including two with possible additional fa } \\
\text { One severe pancreatitis: no evidence of } \\
\text { one herpes simplex encephalitis. }\end{array}$ & \\
\hline
\end{tabular}

preceding death, was found to have a very high concentration of a recently introduced antihypertensive drug; other drug concentrations were satisfactory. The findings on coroner's postmortem performed in 10 out of 11 cases showed pulmonary congestion in nine cases with variable congestion of other organs.

Mean age at death was $28 \cdot 6$ (range 18-34) years and mean duration of epilepsy 20.8 (range 14-30) years. Overall incidence of sudden death was of the order of 1:200 per year in the cohort as a whole (1849 patientyears) and 1:100 per year in those aged 15-34 (1109 patient-years). One patient had severe mental handicap, four others had IQs below 80 and three were living in supervised accommodation. Table 1 shows the classification of the seizure disorders. Three patients had a history of generalised status. All but one were considered medically intractable by their physicians.

Some evidence in favour of a seizure was found in seven of 11 cases (bitten lip (one), bitten tongue (two), found partly or fully off bed (three) with noise heard consistent with seizure (one), death certificate stating seizure (one)). Six of 10 patients where the information was available died after retiring to bed. Eight of these deaths were unwitnessed, and of the remaining three information was not available in one, the onset of the collapse was not witnessed in another, and in the third details were incomplete.

\section{Discussion}

This study shows a significant excess mortality among the cohort studied, with an SMR of $5 \cdot 1(95 \%$ CI $3 \cdot 3-7 \cdot 6)$. In only four cases $(17 \%)$ was death due to underlying disease of which epilepsy was a symptom. At least 14 deaths $(58 \%)$ were considered to be related to epilepsy.

Mean age for the whole cohort was 32.5 with a mean duration of epilepsy of 19 years. The age distribution of the cohort does not reflect that of population based prevalence studies of epilepsy. Children are not covered by the service provided, but older age groups are also under-represented with $88 \%$ of patients aged between 15 and 45 . Only $10 \%$ of the cohort had epilepsy of less than five years in duration, thus limiting the contribution of disease remission. ${ }^{13}$ Referral and discharge patterns, disease severity in relation to age group, and cumulative mortality also need to be considered.

\section{SUDDEN UNEXPECTED DEATHS}

The incidence of sudden unexpected deaths (including those related to seizures) in a cohort with epilepsy seen at specialised hospital outpatient clinics was of the order of 1:200/year. The classification of the seizure disorder largely reflects that of the cohort, with localisation related epilepsy the most common category. Sudden deaths may also occur in patients with primary generalised epilepsy. ${ }^{5}$ 
The mean age of the cases of sudden death was 28.6 years and is consistent with previous studies. Given the age distribution of the cohort, the incidence of sudden death cannot be extrapolated to older age groups or a life long assessment of risk estimated. Mean duration of epilepsy among the patients who died suddenly was $20 \cdot 8$ years. In this respect, the study differs from the Cook County series $^{3}$ where in all 51 cases duration of epilepsy was 10 years or less with a mean age at death of 35. This supports the view that it is age (young adult) rather than duration of epilepsy that defines risk.

As in previous studies, ${ }^{4}$ inaccuracies in death certificates were found, with unsubstantiated status epilepticus recorded as the cause of death in four cases. Mechanisms put forward have included the possible role of ictal cardiac arrhythmias. Hypoxia secondary to apnoea or pulmonary oedema, or other as yet unknown mechanisms such as the release of endogenous opioids peri-ictally, may play a part. Although attention has focused on the nocturnal nature of these deaths, they are mostly not witnessed. That there is often circumstantial evidence for a seizure raises the possibility that a witnessed seizure is less likely to be fatal and reinforces the need to prevent seizures whenever possible.

Epilepsy is often perceived as benign and until recently the message has been that short of seizure related injury epilepsy is not fatal. Yet in 1904, Spratling described epilepsy as "a disease which destroys life suddenly and without warning, through a single, brief attack . ..". ${ }^{14}$ This relatively high incidence of sudden death among a hospital based cohort with chronic epilepsy, although clearly not representative of community based groups, has implications for clinical management. We think that patients with intractable epilepsy contemplating treatment options, whether medical or surgical, should be allowed to consider the small but definite risk of sudden death in making their decisions. Furthermore, patients and their relatives may welcome the opportunity to express intuitive anxieties regarding possible consequences of generalised seizures, and in so doing, keep the risks involved in perspective.

We thank all physicians who kindly responded to our enquiries, the Wellcome Foundation for its help in setting up the study, and Action Research for supporting an ongoing project on sudden death in epilepsy.

1 Hauser WA, Hesdorferr DC. Mortality. In: Epilepsy: frequency, causes and consequences. Maryland: Epilepsy Foundation of USA, 1990.

2 Lathers CM, Schraeder PL. Epilepsy and sudden death. New York: Marcel Dekker, 1990.

3 Leetsma JE, Walczak T, Hughes JR, Kalelkar MB, Teas SS. A prospective study on sudden unexpected death in epilepsy. Ann Neurol 1989;26:195-203.

4 Lip GYH, Brodie MJ. Sudden death in epilepsy: an avoidable outcome? $\mathcal{F} R$ Soc Med 1992;85:609-11.

5 Hirsch CS, Martin DL. Unexpected death in young epileptics. Neurology 1971;21:682-90.

6 Jick SS, Cole TB, Mesher RA, Tennis P, Jick H. Sudden unexplained death in young persons with primary epilepsy. Pharmcoepidemiology Drug Safety 1992;1: 59-64.

7 Klenerman P, Sander JWAS, Shorvon SD. Mortality in patients with epilepsy: a study of patients in long term residential care. I Neurol Neurosurg Psychiatry 1993;56: 149-52.

8 Kahn HA, Sempos CT. Follow-up studies: person-years. In: Statistical methods in epidemiology. New York: Oxford University Press 1989:206-25.

9 Gardner MJ, Altman D. Poisson distribution tables. In: Statistics with confidence. London: BMJ Publications, Statistics with

10 Office of Population Censuses and Surveys. Mortality statistics 1991 (cause, England and Wales). London: HMSO, series DH2 No 18.

11 Morris JA, Gardner MJ. Calculating confidence intervals for relative risks (odds ratios) and standardised ratios and rates, statistics in medicine. BMF 1988;296:1313-6.

12 Commission on Classification and Terminology of the International League against Epilepsy. Proposal for revised classification of epilepsies and epileptic syndromes. Epilepsia 1989;30:389-99.

13 Sander JWAS. Some aspects of prognosis in the epilepsies: a review. Epilepsia 1993;34:1007-16.

14 Spratling WP. Prognosis. In: Epilepsy and its treatment. Philadelphia: W B Saunders, 1904:304. 